\title{
Perbandingan Penghitungan Massa Tubuh Dengan Menggunakan Metode Indeks Massa Tubuh (IMT) dan Bioelectrical Impedance Analysis (BIA)
}

\section{The Comparison of Body Mass Calculation by Using Body Mass Index (BMI) and Bioelectrical Impedance Analysis (BIA) Methods}

\author{
Yonathan Wiranata ${ }^{1}$, Inayatul Inayah ${ }^{2}$ \\ ${ }^{1}$ Prodi Imunologi, Sekolah Pascasarjana, Universitas Airlangga, Surabaya \\ ${ }^{2}$ Ilmu Gizi, Universitas Muhammadiyah Gresik, Gresik \\ Email: yonathanwiranata4@gmail.com, inayah.geogiven@gmail.com
}

\begin{abstract}
ABSTRAK
Indeks Massa Tubuh (IMT) merupakan metode antropometri yang dilakukan dengan mengukur berat badan dan tinggi badan untuk mengklasifikasi nilai berat badan seseorang. Bioelectrical Impedance Analysis (BIA) merupakan metode antropometri yang digunakan untuk menilai komposisi massa tubuh baik massa air, musculoskeletal dan yang utama adalah massa lemak tubuh. Tujuan penelitian ini adalah untuk mengetahui hubungan antara kedua metode antropometri tersebut dan melihat perbandingan hasil dari komposisi massa tubuh. Desain penelitian adalah deskriptif analitik dengan pendekatan cross sectional, tekhnik sampling menggunakan kuota sampling, jumlah sampel 41 responden. Analisis data dengan analisis uji korelasi Pearson (tingkat signifikansi $\alpha=0,05, \mathrm{p}-$ value $<\alpha$ ). Hasil Indeks Massa Tubuh (IMT) 25 responden normal (61\%), hasil Bioelectrical Impedance Analysis (BIA) 29 responden normal (71\%) dengan massa lemak antara $(11,00$ - 37,30, rata - rata 24,05). Didapatkan sebuah hasil hubungan positif antara Indeks Massa Tubuh (IMT) dengan komposisi lemak tubuh $(r=0,708, p<0,000)$. Indeks Massa Tubuh (IMT) dan komposisi lemak tubuh mempunyai hubungan yang signifikan $(\mathrm{p}<0,000)$. Dapat disimpulkan bahwa Indeks Massa Tubuh (IMT) berkorelasi kuat dengan massa lemak tubuh yang diukur dengan menggunakan metode Bioelectrical Impedance Analysis (BIA) namun metode Bioelectrical Impedance Analysis (BIA) tidak lebih baik dari pada metode Indeks Massa Tubuh (IMT) sebagai parameter untuk mengetahui komposisi massa tubuh.
\end{abstract}

Kata Kunci: Indeks Massa Tubuh, Bioelectrical Impedance Analysis, Komposisi Tubuh.

\begin{abstract}
Body Mass Index (BMI) is an anthropometric method performed by measuring the body weight and height to classify one's body mass index. Bioelectrical Impedance Analysis (BIA) is an anthropometric method used to asses the body mass composition, including water mass, musculoskeletal, and mainly the body fat mass. The purpose of this study is to find the relationship between the two methods of anthropometry and to look for the comparison of the body mass composition resulted from the two methods. The design of this study is descriptive analytics with a cross-sectional approach. Sampling technique used is quota sampling, with 41 respondents. Data analysis is conducted through Pearson correlation test analysis (level of significance $\alpha=0.05, p-$ value $<\alpha$ ). The results of this study show that the Body Mass Index (BMI) of 25 respondents is normal (61\%), meanwhile the result from BIA indicates 29 respondents as normal (71\%) with a fat mass between (11.00 to 37.30, 24.05 in average). It is obtained a positive relationship between Body Mass Index (BMI) and the body fat composition ( $r=0.708, p$ $<0.000)$. Body Mass Index (BMI) and the body fat composition have a significant relationship ( $p$ 0.000). In conclusion, Body Mass Index (BMI) has a strong correlation with the body fat mass which is measured by using the Bioelectrical Impedance Analysis (BIA) method. Bioelectrical Impedance Analysis (BIA) method is no better than Body Mass Index (BMI) method as a parameter to determine the body mass composition.
\end{abstract}

Keywords: Body Mass Index, Bioelectrical Impedance Analysis, the body composition 
Yonathan Wiranata : Description of Comparasion of Body Mass Calculation.....

\section{PENDAHULUAN}

Pengukuran komposisi massa tubuh lebih penting daripada hanya sekedar melihat dan menghitung berat badan. Komposisi tubuh menunjukan perbandingan antara massa lemak, massa tulang, jumlah cairan tubuh, jaringan organ dan otot. Rata - rata seseorang mempunyai mempunyai antara 3 - 12 persen lemak esensial, 10 - 22 persen lemak non esensial pada pria dan 20 - 32 persen pada wanita. Komposisi tubuh dapat digunakan untuk mengidentifikasi suatu resiko penyakit dan mengevaluasi status nutrisi seseorang (Haidari et al., 2014). Seorang dikatakan overweight bila berat badannya 10 - 20\% berat badan normal, sedangkan seseorang disebut obesitas apabila kelebihan berat badan mencapai lebih $20 \%$ dari berat normal. Obesitas saat ini menjadi permasalahan dunia bahkan Organisasi Kesehatan Dunia (WHO) mendeklarasikan sebagai epidemic global pada tahan 2016. Menurut data Riset Kesehatan Dasar tahun 2007, prevalensi nasional obesitas umum pada penduduk berusia 15 tahun keatas pada laki - laki sebesar 13,9\% dan pada perempuan sebesar 23,8\%, sedangkan menurut data Estimasi Sasaran Program Kesehatan prevalensi obesitas tahun 2014 mencapai 20,5\% (Konsumsi and Food, 2018).

Antrpometri adalah pengukuran variasi dari dimensi fisik dan komposisi kasar tubuh manusia pada tingkat usia dan status gizi berbeda. Penilaian antropometri dilakukan melalui dimensi fisik dan komposisi kasar tubuh. Hasil pengukuran kemudian dibandingkan dengan standar yang berlaku (Universitas Muhammadiyah Purwokerto. Program Studi Teknik Informatika and Pinandita, 2011). Antropometri dan komposisi tubuh adalah prediksi dari faktor risiko untuk penyakit jantung, diabetes dan banyak jenis kanker maupun penyakit kronis yang terjadi pada orang dewasa. Oleh karena itu antropometri digunakan untuk menentukan komposisi tubuh yang berguna sebagai pengobatan dan pencegahan (Fukunaga et al., 2013). Beberapa metode antropometri seperti Indeks Massa Tubuh (IMT) dan Bioelectrical Impedance Analysis (BIA) yang dapat digunakan untuk menghitung komposisi tubuh suatu individu (Ricciardi and Talbot, 2007). Serangkaian metode yang tersedia untuk penilaian dari komposisi massa tubuh harus mempertimbangkan kriteria penilaian terhadap salah satu kompartemen, 
biaya, validitas dan reabilitas dari nilai yang diperoleh, penerapan teknik, derajat yang dibutuhkan untuk pelatihan pemeriksa, resiko yang terkait dengan paparan radiasi dan ketersediaan peralatan di lembaga kesehatan (Mialich et al., 2014).

Indeks Massa Tubuh (IMT) adalah berat badan dalam kg dibagi dengan kuadrat dari tinggi dalam meter, Indeks Massa Tubuh (IMT) merupakan salah satu cara paling umum digunakan untuk memperkirakan apakah seseorang kelebihan berat badan atau mungkin mengalami masalah kesehatan. Hal ini digunakan karena bagi kebanyakan orang berkorelasi cukup baik dengan tingkat lemak tubuh. Indeks Massa Tubuh (IMT) juga merupakan metode yang relatif mudah,murah dan non invasif. Indeks Massa Tubuh (IMT) memiliki beberapa kekurangan yaitu tidak memberikan indikasi distribusi lemak tubuh dan massa otot (Public Health England, 2015). Sedangkan Bioelectrical Impedance Analysis (BIA) adalah salah satu metode paling popular untuk memperkirakan lemak tubuh. Selain itu Bioelectrical Impedance Analysis (BIA) juga merupakan tindakan non invasif, cepat, mudah, murah dan konsisten yang tersedia dirumah sakit untuk melihat jaringan tubuh, perkiraan total air tubuh dan massa bebas lemak (Shishkova et al., 2007). Studi telah menunjukan bahwa Bioelectrical Impedance Analysis (BIA) juga sangat berkorelasi dengan jaringan adiposa dan subkutan pada semua jenis kelamin dan menjadi cukup efektif karena dapat digunakan secara rutin dalam skala besar (Mittal et al., 2011).

Pemeriksaan baku dalam komposisi tubuh untuk membantu penelitian menggunakan alat tanita metode Bioelectrical Impedance Analysist (BIA). Dipilih ini karena dalam penggunaan lebih mudah dengan biaya yang murah dan cukup lengkap untuk komposisi tubuh daripada metode lain dan dengan tujuan untuk mengetahui apakah terdapat hubungan antara Indeks Massa Tubuh (IMT) dengan kadar lemak total (Archilona, Nugroho and Puruhita, 2016).

\section{METODE}

Jenis penelitian ini merupakan penelitian deskriptif analitik dan pendekatan cross sectional untuk mengetahui gambaran adanya perbedaan komposisi massa tubuh dengan metode Indeks Massa Tubuh (IMT) dan Bioelectrical Impedance Analysis (BIA) diukur menggunakan alat Tanita Scale 
Yonathan Wiranata : Description of Comparasion of Body Mass Calculation.....

BC418 merk Omron. Tempat penelitian ini dilakukan di Universitas Muhammadiyah Malang pada populasi mahasiswa Program Studi S1 Keperawatan angkatan 2012 - 2015 pada bulan Januari tahun 2016. Tehnik sampling yang digunakan adalah sampling kuota dengan besar sampel yang diambil sebanyak 41 mahasiswa. Kriteria inklusi mahasiswa terpilih dengan usia 18 - 25 tahun, kriteria eksklusi mahasiswa dengan edema atau ascites dan tidak bersedia dijadikan sampel. Variabel bebas (Independen) dalam penelitian ini adalah Indeks Massa Tubuh (IMT) dan untuk variabel terikatnya (Dependen) adalah komposisi massa tubuh yang diukur dengan metode Bioelectrical Impedance Analysis (BIA). Untuk pengumpulan data yang pertama dilakukan dengan pengukuran tinggi badan dan berat badan untuk mengetahui kriteria Body Mass Index (BMI) masing - masing responden. Lalu dilakukan pengukuran komposisi massa tubuh dengan metode Bioelectrical Impedance Analysis (BIA) menggunakan Tania Scale untuk mengetahui komposisi tubuh tiap responden. Analisis data secara statistik dilakukan menggunakan program SPSS 16. Diuji dengan korelasi Pearson dan didapatkan nilai p (probalitas untuk menarik kesimpulan).

\section{HASIL}

Penelitian dilakukan terhadap 41 sampel pada mahasiswa Universitas Muhammadiyah Malang Program Studi S1 Keperawatan angkatan 2012 - 2015. Diukur nilai BMI dengan berat badan dan tinggi badan kemudian diukur komposisi massa tubuh dengan metode Bioelectrical Impedance Analysis (BIA) menggunakan Tanita Scale BC418. Kemudian didapatkan data bahwa responden dengan usia minimum yaitu umur 17 tahun (7\%), 18 tahun (12\%), 19 tahun (5\%), 20 tahun (10\%), 21 tahun (42\%), 22 tahun (22\%) dan dengan usia maksimal adalah umur 23 tahun (2\%), sedangkan rata - rata usia responden adalah 20,4 tahun. 


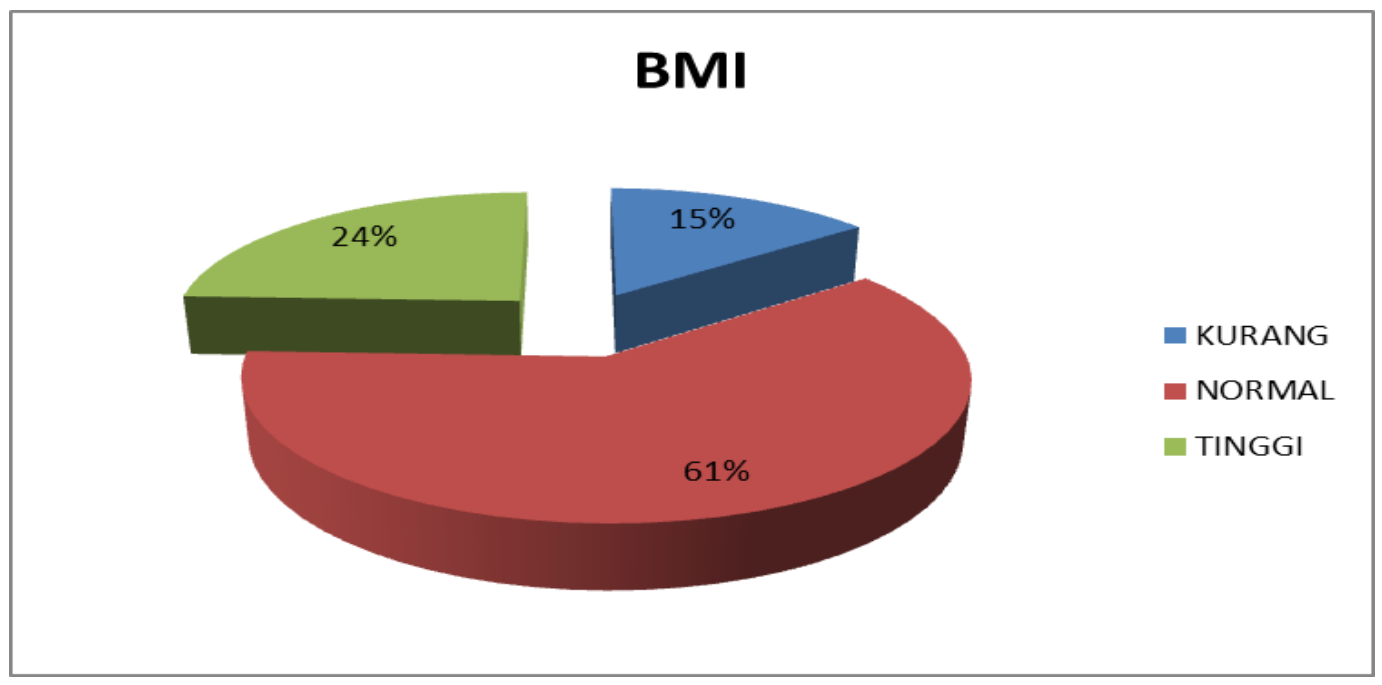

Gambar 1 Data Distribusi Frekuensi Gambaran Pengukuran Komposisi Massa

Tubuh Dengan Menggunakan Metode Body Mass Index (BMI)

Berdasarkan gambar 1 diatas, dapat diketahui bahwa dari 41 responden terdapat 6 responden (15\%) memiliki hasil Body Mass Index (BMI) kurang, 25 responden (61\%) memiliki hasil Body Mass Index (BMI) normal dan 10 responden (24\%) memiliki hasil Body Mass Index (BMI) lebih, tinggi badan minimum responden adalah $150 \mathrm{~cm}$ dan maksimal $182 \mathrm{~cm}$ dengan nilai rata - rata $160 \mathrm{~cm}$ sedangkan untuk berat badan minimum adalah $38 \mathrm{~kg}$ dan maksimal 100 kg dengan nilai rata - rata $56 \mathrm{~kg}$.

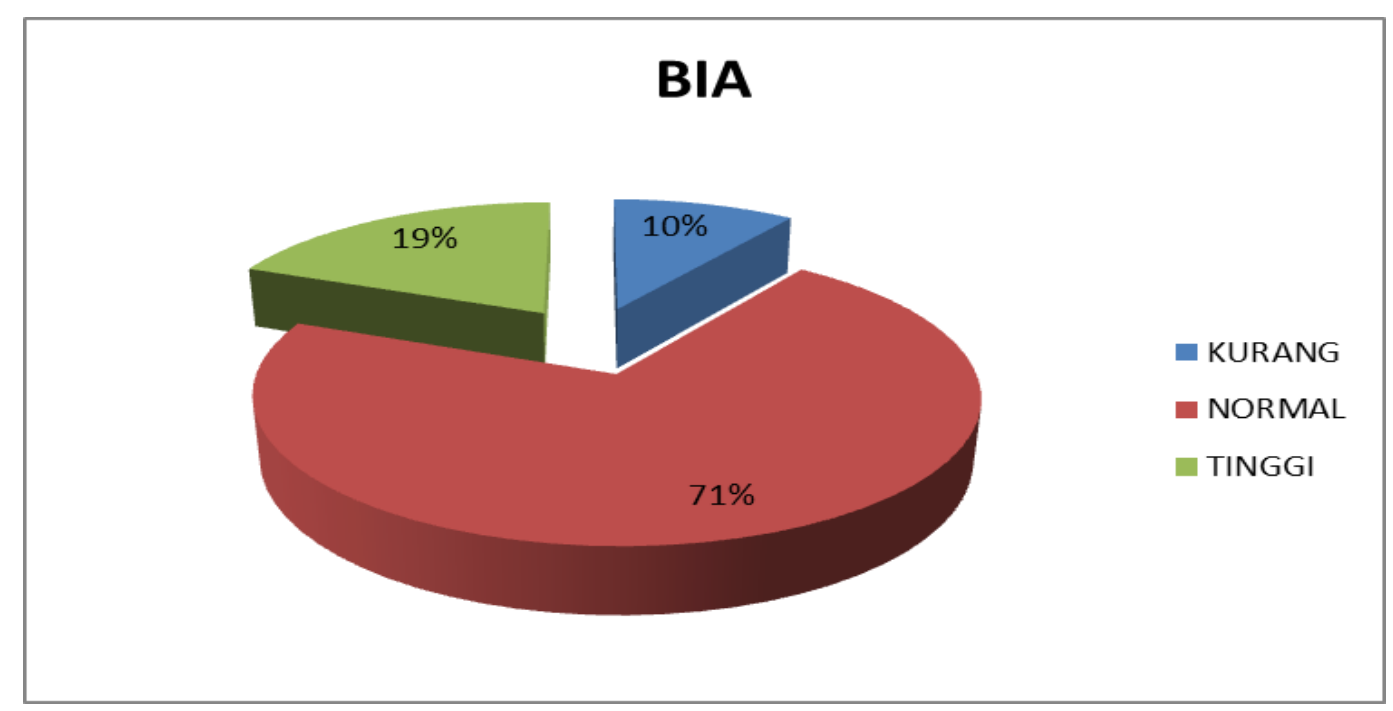

Gambar 2 Data Distribusi Frekuensi Gambaran Pengukuran Komposisi Massa Tubuh Dengan Menggunakan Metode Bioelectrical Impedance Analysis (BIA) 
Yonathan Wiranata : Description of Comparasion of Body Mass Calculation.....

Berdasarkan diagram 3 dan table 3 diatas, dapat diketahui bahwa dari 41 responden terdapat 4 responden (10\%) memiliki komposisi massa tubuh kurang, 29 responden (71\%) memiliki komposisi massa tubuh normal dan 8 responden (19\%) memiliki komposisi massa tubuh tinggi jika dihitung dengan menggunakan metode Bioelectrical Impedance Analysis (BIA), didapatkan nilai minimum massa musculo 1,69 kg dan nilai maksimal 3,32 kg dengan nilai rata - rata 2,2 kg. Untuk nilai minimum massa lemak adalah 11\% dan maksimal 37,3\% dengan nilai rata rata 24\%. Sedangkan untuk nilai massa air terendah adalah 45,9\% dan maksimal $65 \%$ dengan nilai rata - rata 53,33\%.
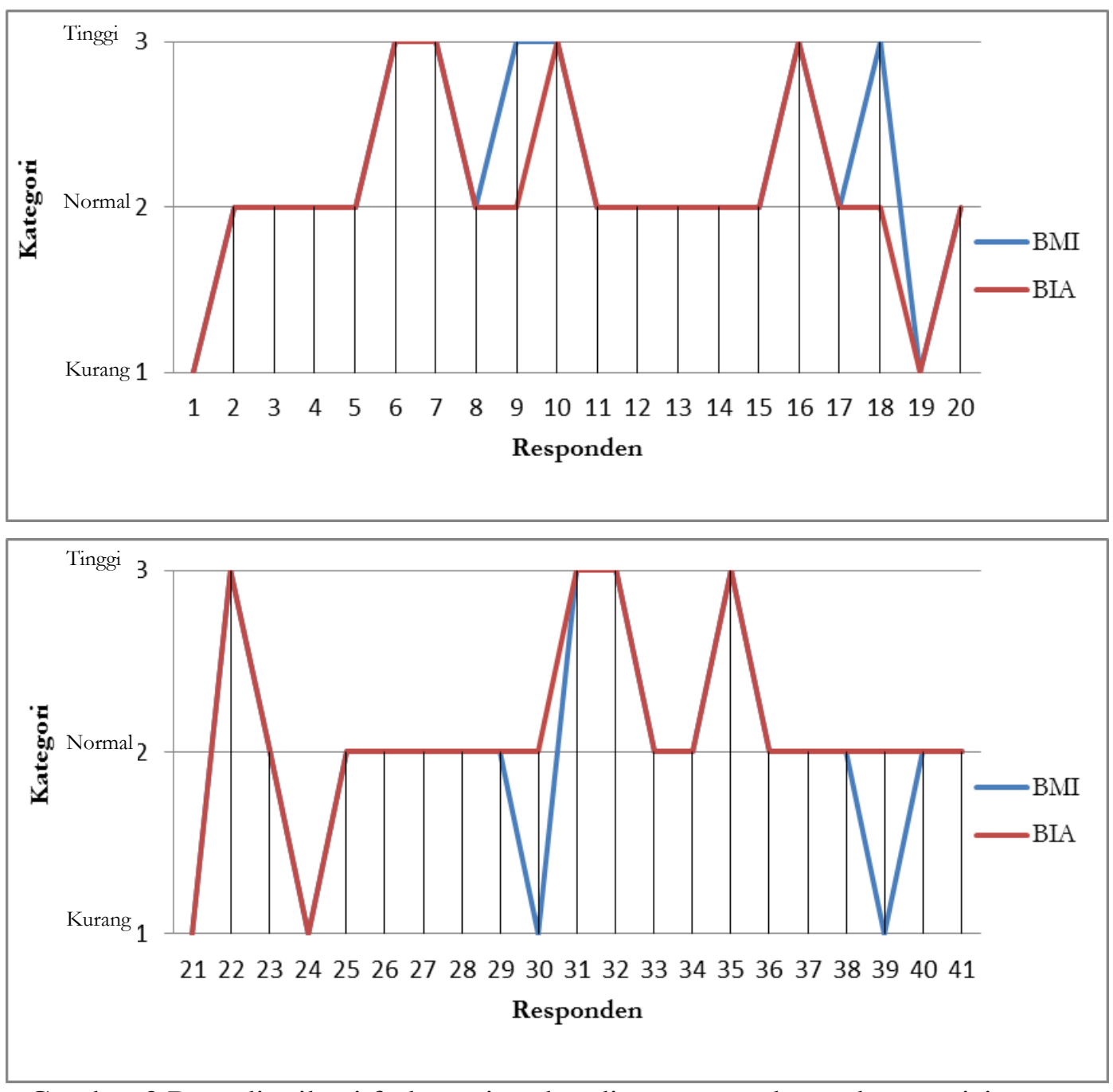

Gambar 3 Data distribusi frekuensi perbandingan pengukuran komposisi massa tubuh dengan menggunakan metode Body Mass Index (BMI) dan Bioelectrical Impedance Analysis (BIA) 
Jurnal Manajemen Kesehatan Yayasan RS.Dr.Soetomo Vol.6 No.1 April 2020 :

Berdasarkan diagram 4 diatas dijelaskan hasil penghitungan komposisi massa tubuh dengan menggunakan metode Body Mass Index (BMI) dan Bioelectrical Impedance Analysis (BIA) serta nomor responden. Hasil 1 menunjukan komposisi kurang, 2 menunjukan komposisi normal dan 3 menunjukan komposisi tinggi. Didapatkan perbandingan hasil dengan menggunakan 2 metode tersebut adalah 37 responden memiliki hasil komposisi tubuh yang sama dengan menggunakan metode Body Mass Index (BMI) dan Bioelectrical Impedance Analysis (BIA) sedangkan 4 responden memiliki hasil komposisi tubuh yang berbeda pada responden dengan nomor 9, 18, 30 dan 39.

Berdasarkan Tabel 3 diatas diperoleh nilai p - value 0,000 ( $\mathrm{p}<0,05)$, yang artinya ada hubungan antara Indeks Massa Tubuh (IMT) dengan komposisi massa lemak tubuh. Sedangkan hasil uji korelasi Pearson diketahui bahwa nilai yang didapatkan $+0,708$ yang menunjukan bahwa adanya korelasi atau hubungan yang kuat. Sedangkan nilai korelasi sebesar +.708 dapat diartikan sebagai korelasi positif yaitu dimana semakin tinggi nilai Indeks Massa Tubuh (IMT) maka semakin tinggi pula nilai lemak tubuh dengan metode Bioelectrical Impedance Analysis BIA.

\section{PEMBAHASAN}

Hasil uji statistik yang telah dilakukan oleh peneliti didapatkan bahwa IMT dengan komposisi massa lemak tubuh dalam metode BIA mempunyai hubungan yang kuat dan positif. Hal ini didukung oleh beberapa penelitian yang telah dilakukan sebelumnya, (Ranasinghe et al., 2013) menyatakan IMT digunakan sebagai pengukuran tingkat populasi yang berguna mengetahui kelebihan berat badan dan obesitas. Hal ini berlaku sama untuk semua jenis kelamin usia dewasa. Populasi yang diambil adalah 1114 responden laki - laki dikelompokkan menjadi 3 kelompok yaitu usia 18 - 39, usia 40 - 59 dan usia >60 tahun, lalu disimpulkan bahwa metode IMT berkorelasi dengan massa lemak yang diukur dengan metode BIA pada populasi di Asia Selatan. (Heydari, Ayatollahi and Zare, 2011) dalam jurnal penelitiannya di negara Iran melakukan prevalensi obesitas dan kelebihan berat badan menggunakan metode IMT dan BIA pada 288 
Yonathan Wiranata : Description of Comparasion of Body Mass Calculation.....

siswa dan disimpulkan bahwa kedua metode tersebut sangat berkorelasi erat dalam mendeteksi obesitas, namun keterbatasan dalam penelitiannya adalah populasi dan sampel penelitian yang digunakan hanya dalam mahasiswa saja, jelas indeks ini harus dievaluasi pada populasi lain juga. Sebuah penelitian yang dilakukan dengan lebih dari 12.000 sampel pada pria dan wanita yang meneliti korelasi antara Indeks Massa Tubuh (IMT) dan Bioelectrical Impedance Analysis (BIA) dengan empat penanda biologis yang diketahui menverminkan kondisi medis terkait obesitas, menemukan bahwa Indeks Massa Tubuh (IMT) memiliki korelasi tertinggi di seluruh penanda biologis, meskipun tidak ada perbandingan langsung antara Bioelectrical Impedance Analysis (BIA) dan Indeks Massa Tubuh (IMT) dalam menilai adipositas tubuh dilakukan selama penelitian sehingga disimpulkan Bioelectrical Impedance Analysis (BIA) tidak lebih unggul sebagai prediktor adipositas keseluruhan pada populasi umum (Peltz et al., 2010).

\section{SIMPULAN}

Berdasarkan hasil penelitian dan pembahasan yang telah dilakukan, maka dapat disimpulkan bahwa untuk mengetahui hasil komposisi massa tubuh manusia khususnya massa lemak tubuh tidak perlu menggunakan 2 buah metode yang berbeda yaitu Indeks Massa Tubuh (IMT) dan Bioelectrical Impedance Analysis (BIA) karena sudah diketahui bahwa hasil dari Indeks Massa Tubuh (IMT) sendiri memiliki hubungan dan berkorelasi baik dengan komposisi lemak tubuh yang diukur dengan menggunakan metode Bioelectrical Impedance Analysis (BIA), jadi cukup dilakukan salah satu metode saja sebagai parameter prediksi untuk menentukan komposisi tubuh seseorang, dengan manfaat yang bisa diterapkan dalam dunia medis dan kesehatan bahwa nilai Indeks Massa Tubuh (IMT) ataupun komposisi massa tubuh dengan metode Bioelectrical Impedance Analysis (BIA) bisa sebagai prediksi untuk mencegah dan mengurangi kasus kelebihan berat badan dan obesitas.

\section{UCAPAN TERIMA KASIH}

Peneliti mengucapkan terima kasih kepada staf Tata Usaha Fakultas Ilmu Kesehatan Universitas Muhammadiyah Malang yang membantu dalam izin penelitian ini. 
Jurnal Manajemen Kesehatan Yayasan RS.Dr.Soetomo Vol.6 No.1 April 2020 :

\section{DAFTAR PUSTAKA}

Archilona, Z. Y., Nugroho, K. H., \& Puruhita, N. (2016). Kadar Lemak Total (Studi Kasus Pada Mahasiswa Kedokteran Undip). Jurnal Kedokteran Dipenogoro, 5(2), 122-131.

Fukunaga, Y., Takai, Y., Yoshimoto, T., Fujita, E., Yamamoto, M., \& Kanehisa, H. (2013). Influence of maturation on anthropometry and body composition in Japanese junior high school students. Journal of Physiological Anthropology, 32(1), 1. https://doi.org/10.1186/1880-6805-32-5

Gurenlian, J. R. (2014). The power of prevention. International Journal of Dental Hygiene, 12(1), 1-1. https://doi.org/10.1111/idh.12067

Haidari, F., Shirbeigi, E., Cheraghpour, M., \& Mohammadshahi, M. (2014). Association of dietary patterns with body mass index, waist circumference, and blood pressure in an adult population in Ahvaz, Iran. Saudi Medical Journal, 35(9), 967-974.

Heydari, S. T., Ayatollahi, S. M. T., \& Zare, N. (2011). Diagnostic value of bioelectrical impedance analysis versus body mass index for detection of obesity among students. Asian Journal of Sports Medicine, 2(2), 68-74. https://doi.org/10.5812/asjsm.34777

Konsumsi, P., \& Food, F. (2018). Pola Konsumsi Fast Food, Aktivitas Fisik dan Faktor Keturunan Terhadap Kejadian Obesitas (Studi Kasus pada Siswa SD Negeri 01 Tonjong Kecamatan Tonjong Kebupaten Brebes). Public Health Perspective Journal, 2(3), 262-269.

Mialich, M. S., Maria, J., Sicchieri, F., Afonso, A., \& Junior, J. (2014). Analysis of Body Composition : A Critical Review of the Use of Bioelectrical Impedance Analysis. International Journal of Clinical Nutrition, 2014, Vol. 2, No. 1, 1-10, 2(1), 1-10. https://doi.org/10.12691/ijcn-2-1-1

Mittal, R., Goyal, M. M., Dasude, R. C., Quazi, S. Z., \& Basak, A. (2011). Measuring obesity: results are poles apart obtained by BMI and bio-electrical impedance analysis. Journal of Biomedical Science and Engineering, 04(11), 677-683. https://doi.org/10.4236/jbise.2011.411084

Peltz, G., Aguirre, M. T., Sanderson, M., \& Fadden, M. K. (2010). The role of fat mass index in determining obesity. American Journal of Human Biology, 22(5), 639-647. https://doi.org/10.1002/ajhb.21056

Public Health England. (2015). Statistics on Obesity, Physical Activity and Diet England 2015 Statistics on Obesity, Physical Activity and Diet: England 2015. Statistics on Obesity, Physical Activity and Diet, February.

Ranasinghe, C., Gamage, P., Katulanda, P., Andraweera, N., Thilakarathne, S., \& Tharanga, P. (2013). Relationship between Body mass index (BMI) and body fat percentage, estimated by bioelectrical impedance, in a group of Sri Lankan adults: A cross sectional study. BMC Public Health, 13(1), 1. https://doi.org/10.1186/1471-2458-13-797

Ricciardi, R., \& Talbot, L. A. (2007). Use of bioelectrical impedance analysis in the evaluation, treatment, and prevention of overweight and obesity. Journal of the American Academy of Nurse Practitioners, 19(5), 235-241. https://doi.org/10.1111/j.1745-7599.2007.00220.x 
Yonathan Wiranata : Description of Comparasion of Body Mass Calculation.....

Shishkova, A., Petrova, P., Tonev, A., Bahlova, P., Softov, O., \& Kalchev, E. (2007). Analysis of body composition in overweight and obese women using bioimpedance (BIA) system. Journal of IMAB, 13(1), 8-12.

Universitas Muhammadiyah Purwokerto. Program Studi Teknik Informatika, B. J., \& Pinandita, T. (2011). Juita. Juita, I(4), 157-168. https://www.neliti.com/publications/92701/rancang-bangun-aplikasi-mobileperhitungan-indeks-massa-tubuh-dan-berat-badan-id

\begin{tabular}{|l|l|}
\hline Submission & 6 Desember 2019 \\
\hline Review & 9 Januari 2020 \\
\hline Accept & 29 Maret 2020 \\
\hline Publish & 22 April 2020 \\
\hline DOI & $10.29241 /$ jmk.v\%vi\%i.280 \\
\hline Sinta Level & 4 (Empat) \\
\hline
\end{tabular}

